\title{
La ivermectina no redujo el tiempo de resolución de los síntomas en adultos con COVID-19 leve
}

\author{
Ivermectin did not reduce the symptom resolution time in adults with mild COVID-19
}

\section{Comentado de:}

López-Medina E, et al. JAMA. 2021;325(14):1426-1435. PMID: $33662102^{1}$

\section{Objetivo}

Determinar la eficacia de la ivermectina como tratamiento para el COVID-19 leve en comparación con placebo.

\section{Diseño, lugar y pacientes}

Ensayo aleatorizado, doble ciego (investigadores y pacientes) realizado en Cali, Colombia. Los potenciales participantes del estudio fueron identificados mediante un muestreo aleatorio simple de la base de datos del Departamento de Salud del Estado de pacientes con COVID-19 sintomático confirmado por prueba de antígeno o reacción de PCR del SARS-CoV-2. Fueron reclutados un total de 476 pacientes adultos ambulatorios $u$ hospitalizados con enfermedad leve y sintomática durante siete días o menos, sin requerimiento de oxígeno nasal de alto flujo o ventilación mecánica (invasiva o no invasiva) entre julio y noviembre de 2020, con seguimiento hasta diciembre del mismo año.

Fueron exlcluidas las mujeres embarazadas, los pacientes asintomáticos, quienes tenían una neumonía grave, aquellos tratados con ivermectina durante los cinco días anteriores o que tuvieron disfunción hepática. Los pacientes elegibles fueron asignados al azar en una proporción de 1: 1 para recibir ivermectina oral o placebo.

\section{Intervención}

La ivermectina oral fue administrada en dosis de $300 \mu \mathrm{g} / \mathrm{kg} / \mathrm{día}$ durante cinco días. Los frascos de ivermectina y de placebo fueron idénticos. Las enfermeras de campo estaban cegadas a la intervención asignada a cada paciente, que fue provista por un farmacéutico no cegado.

\section{Medición de resultados principales}

El resultado primario fue el tiempo transcurrido desde la aleatorización hasta la resolución completa de los síntomas, durante el período de seguimiento de 21 días. También fueron rerecolec- tados los eventos adversos.

\section{Resultados principales}

En el transcurso del estudio, se detectó que 76 pacientes habían recibido ivermectina y ninguno de ellos placebo debido a un error en el etiquetado del producto de investigación, motivo por el cual fueron excluidos del análisis primario (por intención de tratar). Entre los 400 pacientes que fueron aleatorizados en la población de análisis primaria, $398(99,5 \%)$ completaron el ensayo. La mediana de edad fue de 37 años (intervalo intercuartílico [IIC] 29 a 48) y $58 \%$ eran mujeres. La mediana del tiempo hasta la resolución de los síntomas fue 10 días (IIC 9 a 13) en el grupo que recibió ivermectina en comparación con 12 días (IIC 9 a 13) en el grupo asignado a placebo (Diferencia -2 días, RIC -4 a 2 hazard ratio para la resolución de los síntomas 1,07; intervalo de confianza [IC] del $95 \% 0,87$ a 1,32). Para el día 21 , el $82 \%$ de los participantes del grupo de ivermectina y el $79 \%$ del grupo de placebo habían resuelto los síntomas.

La ivermectina tampoco redujo la asistencia a la central de emergencias o las consultas telefónicas (1,43\% más en el grupo ivermectina, IC $95 \%-3,67$ a 6,54), lo que respalda aún más la falta de eficacia para esta terapéutica.

El evento adverso más común fue el dolor de cabeza, informado por 104 pacientes (52\%) que recibieron ivermectina y 111 (56\%) que recibieron placebo. El evento adverso grave más frecuente fue el fallo multiorgánico, que se produjo en cuatro pacientes (dos en cada grupo). Sólo se registró una muerte en el grupo asignado a placebo.

\section{Conclusión}

Entre los adultos con COVID-19 leve, un ciclo de cinco días de ivermectina, en comparación con placebo, no mejoró significativamente el tiempo hasta la resolución de los síntomas. Estos hallazgos no apoyan el uso de ivermectina para el tratamiento del COVID-19 leve, aunque pueden ser necesarios ensayos más grandes para comprender los efectos de la ivermectina respecto de otros desenlaces clínicamente relevantes.

\section{Comentario}

Resulta clave encontrar los enfoques terapéuticos que puedan mejorar los desenlaces de los pacientes con COVID-19. Es conocido que la replicación vírica puede ser especialmente activa al principio del curso de esta enfermedad ${ }^{2}$ y los estudios experimentales in-vitro habían demostrado actividad antivírica de la ivermectina en las primeras fases de otras infecciones virales. La ivermectina es un fármaco ampliamente utilizado que actúa en diferentes sitios de unión a proteínas para reducir la replicación viral ${ }^{3}$ con un perfil de seguridad favorable ${ }^{4}$. Varios países la utilizan ${ }^{5-7}$, lo que ha provocando un aumento en la demanda local del medicamento.

En este ensayo clínico aleatorizado (ECA) que incluyó 476 pacientes, la duración de los síntomas entre los tratados con ivermectina fue dos días menor que los tratados con placebo, pero esta diferencia no fue estadísticamente significativa ni clínicamente relevante. La población de estudio fue relativamente joven y saludable, con pocas comorbilidades, niveles de enzimas hepáticas inferiores a 1,5 veces el nivel normal y rara vez desarrolló complicaciones (incidencia de deterioro clínico inferior al $3 \%$ ), lo que podría explicar que el estudio tuviera un poder insuficiente para detectar tal efecto.

El estudio tuvo diversas limitaciones, como el cambio del desenlace primario original en la sexta semana, la falta de evaluaciones virológicas además de las evaluaciones clínicas, y por último, que el placebo y la ivermectina difirieron en ciertas características organolépticas, como el olor y el sabor, durante los primeros 65 pacientes.

Por los motivos enunciados, el uso de la ivermectina para prevenir la progresión del COVID-19 leve a estadios más graves debería evaluarse en ensayos más grandes y en poblaciones que incluyan pacientes de mayor edad, más sintomáticos y 
con más comorbilidades. Los hallazgos pueden ser generalizables sólo a las poblaciones menos vulnerables como las del estudio.

Si bien en un meta-análisis ${ }^{8}$ se observó un efecto beneficioso en términos de mortalidad en poblaciones más diversas, la muy baja certeza de la evidencia en cuanto a este desenlace duro no permite aún hacer recomendaciones. Desafortunadamente, este estudio no permitió mejorar la precisión de los resultados sobre mortalidad ya que sólo se reportó una muerte. Los ECA más grandes en curso en la actualidad, realizados en México, Sudamérica y Egipto, con resultados esperados en febrero y marzo de 2021, podrían mejorar esta certeza de la evidencia ${ }^{9}$. Por otro lado, una revisión sistemática viva, que incluyó el estudio que comentamos, concluyó que, basándonos en los únicos cuatro ECA clasificados como de bajo riesgo de sesgo, la ivermectina puede no reducir significativamente la mortalidad y probablemente no mejore el tiempo de resolución de los síntomas, aunque se necesitan más investigaciones para confirmar estos hallazgos ${ }^{10}$.

\section{Conclusiones de los comentadores}

El uso de la ivermectina en los pacientes con COVID-19 sigue siendo controvertido, ya que este estudio no demostró superioridad clínica ni estadística. Las guías terapéuticas de los diferentes países difieren ampliamente en su recomendación. En Argentina, varias provincias adoptaron oficialmente su uso y en otras los médicos la indican informalmente, sin un marco normativo. Es de especial importancia, frente a este escenario, generar un criterio unificado que indique recomendaciones y le brinde a este fármaco un margen regulatorio terapéutico para administrar a los pacientes el mejor tratamiento posible.

Agustín Ciapponi [ Servicio de Medicina Familiar y Comunitaria, Hospital Italiano de Buenos Aires. aciapponi@gmail.com ]

Victoria Sol Cabrera [ Carrera de Medicina, Instituto Universitario Hospital Italiano de Buenos Aires. victoria.cabrera@hospitalitaliano.org.ar ]

Ciapponi A, Cabrera VS. La ivermectina no redujo el tiempo de resolución de los síntomas en adultos con COVID-19 leve. Evid Actual Pract Ambul. 2021;24(2):e002128. Comentado de: López-Medina E, et al. Effect of Ivermectin on Time to Resolution of Symptoms Among Adults With Mild COVID-19: A Randomized Clinical Trial. JAMA. 2021;325(14):1426-1435. PMID: 33662102

\section{Referencias}

1. López-Medina E, López P, Hurtado IC, et al. Effect of Ivermectin on Time to Resolution of Symptoms Among Adults With Mild COVID-19: A Randomized Clinical Trial. JAMA. 2021;325(14):1426-1435. Available from: 10.1001/jama.2021.3071.

2. Siddiqi HK, Mehra MR. COVID-19 illness in native and immunosuppressed states: A clinical-therapeutic staging proposal. J Heart Lung Transplant. 2020;39(5):405-407. Available from: 10.1016/j.healun.2020.03.012;https://dx.doi.org/10.1016/j.healun.2020.03.012.

3. Yang S, Atkinson S, Wang C. The broad spectrum antiviral ivermectin targets the host nuclear transport importin $\alpha / \beta 1$ heterodimer. Antiviral Res. 2020;177:104760-104760. Available from: 10.1016/j.antiviral.2020.104760.

4. Omura S. Ivermectin: 25 years and still going strong. Int J Antimicrob Agents. 2008;31(2):91-98. Available from: 10.1016/j.ijantimicag.2007.08.023.

5. República del Perú, Ministerio de Salud. Resolución ministerial No. 270-2020-MINSA; 2020. Available from: https:/www.gob.pe/institucion/minsa/ normas-legales/563764-270-2020-minsa [Last access: 2021-05-19].

6. Rodriguez-Mega E. Latin America's embrace of an unproven COVID treatment is hindering drug trials. Nature. 2020;586(7830):481-482. Available from: 10.1038/d41586-020-02958-2.

7. Gobierno Del Estado Plurinacional De Bolivia, Ministerio De Salud. Resolución ministerial No. 0259; 2020. Available from: https://www.minsalud. gob.bo/component/jdownloads/?task=download.send\&id=425\&catid=27\&m=0\&ltemid=646 [Last access: 2021-05-19].

8. Hill A, Abdulamir A, Ahmed S, et al.. Meta-analysis of randomized trials of ivermectin to treat SARS-CoV-2 infection; 2021. Available from: 10.21203/ rs.3.rs-148845/v1; https://www.researchsquare.com/article/rs-148845/v1.

9. Ciapponi A. Meta-análisis preliminar de ensayos clínicos aleatorizados de ivermectina para tratar la infección por SARS-CoV-2. Evid actual pract ambul. 2021;24(1):e002117. Available from: 10.51987/EVIDENCIA.V24I1.6913;http://www.evidencia.org/index.php/Evidencia/article/view/6913.

10. Ongoing Living Update of COVID-19 Therapeutic Options: Summary of Evidence. Rapid Review. PAHO/IMS/EIH/COVID-19/21-015; 2021. Available from: https://iris.paho.org/bitstream/handle/10665.2/52719/PAHOIMSEIHCOVID-1921015_eng.pdf?sequence=39\&isAllowed=y. 